\title{
Elastoplastic behaviour of T, Y, DT and DY-tubular joints under axial loading
}

\author{
Salah Eddine Jalal ${ }^{1}$, Lahbib Bousshine ${ }^{2}$ \\ ${ }^{1,2}$ (Laboratory of construction technology and industrial systems, High National School of Electricity and \\ Mechanic/ Hassan II University, Casablanca, Morocco)
}

\begin{abstract}
The offshore tubular structures are composed of beam elements which the intersecting areas present structural discontinuities. So, a high stress concentration appears in these areas, particularly, in the hot spots points. In this study, the finite element method (FEM) is applied on welded tubular T, Y, DT and DY-joints, in order to visualise the elastic stress distribution in the vicinity of the weld toe, and record the plastic limit load of each form. The aim of this work is to compare the elastic and elastoplastic behaviours, firstly, between $T$ and $Y$ tubular join, then, repeated this study for DT and DY joints. For elastic study, the evolution of von Mises equivalent stress along the weld toe was compared, knowing that the axial loads are applied in the free ends of the all braces. For nonlinear investigation, a comparison of tensile loads limits (collapse load) of these joints was realised, knowing that a tensile proportionally load is applied in the free ands of the braces. The mesh and the numerical calculation are performed using, respectively, Patran and Nastran software.
\end{abstract}

Keywords - Elastic, Elastoplastic, Stress Factor Concentration, Tubular Joint, Hot Spot, Limit Load.

\section{Introduction}

The welded assemblies are often used in the many industrial construction types; pressure equipments, pipelines, canalizations, racks, masts for telecommunications, monopods for the electrical power transport, industrial buildings and metallic offshore structures, in particularly, supports of offshore petroleum structures, called Jacket. This gigantic structure is manufacturing, generally, by tubular profiles welded together for to create joints in different geometrical forms (T, Y, K, KT, DT, DY, DK, DKT ...). When the offshore petroleum station is in operation, two kinds of mechanical failures can occur:

- Damage trough the elastic fatigue phenomenon caused by repeated or alternate loading following the spectral functions (waves, water flow, high and low tide, strong and low winds,...) whose give rise to a large number of stress cycles which combined in the hot spots, for lead finally to cracking by fatigue phenomenon.

- Damage by elastoplastic strains, caused by increasing monotonic loading which give the dislocations phenomenon in vicinity of the weld toe. The plasticization material is primed, always, by a hot spot.

In this work, both cases will be studied:

- Elastic study: The comparison of the local stresses level developed along the weld toe. Firstly, this work will be realised for planar joints (T and Y). Subsequently, it's repeated for multi-planar shapes, i.e. DT and DYjoints. In this case, all joints are solicited in unbalanced tension applied at free ends of braces.

- Elastoplastic study: To compare load limits and load limits factors of all assemblies study, following an axial increasing proportional load applied at free ends of braces. The diffusion of plastic areas in these joints will be, also, analysed.

\section{Bibliographic Studies}

In the field of welded tubular joints, the majority of previous works is the elastic studies. For to search the hot spot positions, the T-joint have been subjected, numerically, to different types of basic loading as in axial tension, axial compression, in-plane bending and out-of-plane bending [1], it has been shown that for axial loading (TEN) and (OPB), hot spots coincide with the two Crown points. But four hot spots appear when the specimen is loaded in (IPB). They are located between saddle and crown. In other work, the hot spot positions has been confirmed experimentally for T-joints but this study was limited, only, to TRA and IPB tests [2]. Ghanameh et al. [3] performed a numerical simulation for the same type of joints, in aim to determine the curves SFC- $\psi$ following the axial loading combined with deviated moments. Through this study, it became possible to define the curves that represent the maximum and minimum stress concentration factor corresponding to all possible loadings. Moreover, a polar representation of these two functions ( $\min$ and max) became possible, therefore, clear and easy detection of hot spots. Elsewhere, little elastoplastic researches were carried. In aim to establish stiff joints database, the numerical studies have been performed for DT and T-joint stiffened by using inner circular rings [4,5]. For each same form, the results showed that the load-diplacement curves are identical for stiffened and unstiffened joint. Also, it has been proven that the propagation mode of the plastic region is almost the same. A comparative study of elastoplastic behaviour of DT-joint has been performed [6]. This joint 
is subjected to compressive loading applied simultaneously to the free ends of chord and two braces. The numerical simulation and test results showed that the ultimate adimensional load increases in term of adimensional loads ratio applied in chord and braces. We note that the results of the numerical simulation are conservative [6]. The influence of longitudinal gap parameter and chord thickness ratio to elastoplastic behaviour for DK-joint under antsymmetrical tensile has been analysed [7]. This numerical study, based on three-dimensional meshing, has been proven that the ultimate load decreases with increasing chord thickness ratio and/or the relative longitudinal gap parameter. A comparative study was performed for three types of Tjoints [8]. Type 1 represents the models where the brace is perpendicular to the circular chord outer diameter and type 2 represents the models where the brace is perpendicular to the elliptical chord minor diameter, while type 3 represents models where the brace is perpendicular to the elliptical chord major diameter. Tests and numerical simulations have shown, for each type of load, that the assembly's rigidity for type 1 is located between those of the two others. An experimental study with a numerical simulation was performed for T-joints [9]. Nine specimens, of the same size, were selected for this work. Three specimens are used for axial loading tests, three for IPB tests and three for OPB tests. The experimental results are compared with those of the numerical simulation, which showed a perfect agreement in the tension case. The gap observed in the plastic range, in the cases of bending between test results and numerical simulation, is explained by the absence of the hardening effect and the geometrical instability phenomenon in the numerical simulation (elastic perfectly plastic behaviour), but the good agreements are observed in the elastic range.

\section{Choice Joints and Meshing}

For to compare elastic and elastoplastic tubular joints behaviours, the numerical specimens are chosen with the same dimensions and different shapes (Fig. 1). Previous studies have shown that the mesh with 2D elements gives results close to reality that mesh with 3D elements [10,11]. In this work, the mesh is made with thin shell elements of quadrilaterals form using Patran software. A mesh refinement is achieved in the intersection areas in aim to increase the calculation accuracy and levy the big number of stress values along the weld toe. So, in this area, it may levy sixty four stress values, i.e. with angular pith equal to $5.625^{\circ}$. This will display, in a meaningful way, the local stress variation in term of $\psi$ in the weld toe vicinity.

The material chosen for this study is a steel which Young's modulus E=2.1e5MPa, Poisson's ratio $v=0.33$ and yield stress $\sigma_{\mathrm{e}}=240 \mathrm{MPa}$.

DT and DY-joints are obtained from the $\mathrm{T}$ and $\mathrm{Y}$-joints following a rotation about the chord axis at an angle $90^{\circ}$. Thus, the convergence study of mesh was performed only for the T and Y-joints (Fig. 2).

\section{Loading and boundary conditions}

\section{Elastic responses}

For all the joints studied, the chord free ends are clamped, and a force equal to $90 \mathrm{kN}$ is applied to the free end of each brace. A rigid node is created at the ends of the all structural elements. So, the forces and boundary conditions are applied at these nodes (Fig. 3).

\section{Results and analysis}

Figure 4 shows a comparison between the geometric stresses recorded along the weld toe for the two planar joints $\mathrm{T}$ and $\mathrm{Y}$, with same dimensions, solicited in tension. For both forms, we observe that the hot spots is located in saddle with a maximal stress equal to $255 \mathrm{MPa}$ for the T-joint and $144 \mathrm{MPa}$ for the $\mathrm{Y}$-joint. At crowns, the local stress is very low. It's equal to $17.8 \mathrm{MPa}$ at crown for the T-joint and at toe crown for the Yjoint. Moreover, we observe that the level of the hot spot (saddle in this load case), the maximum stress of the Tjoint is greater than that of the $\mathrm{Y}$-joint with a ratio equal to 1.78. This proves that the $\mathrm{Y}$ form is more robust than $\mathrm{T}$ form.

Figure 5 reflects the graphical comparison of the stresses developed around the weld toe for multiplanar shapes DT and DY. The crown heel and outer saddle are chosen as reference points. These two points are listed by $\psi=0$ and $\psi=90^{\circ}$ respectively. We observe that the hot spot coincides with outer saddle with a stress equal to $184.5 \mathrm{MPa}$ for DT-joint and 103.7 for DY-joint.

For both shapes, the inner saddle is in safety all the time, with a von Mises equivalent stress equal to 70.4MPa for DT-joint and 34MPa for DY-joint. The value 18.2MPa is registered at crown of DT-joint. In crown of DY-joint (toe and heel), the values 18.2MPa and 11.6MPa are registered respectively (Fig. 5). 


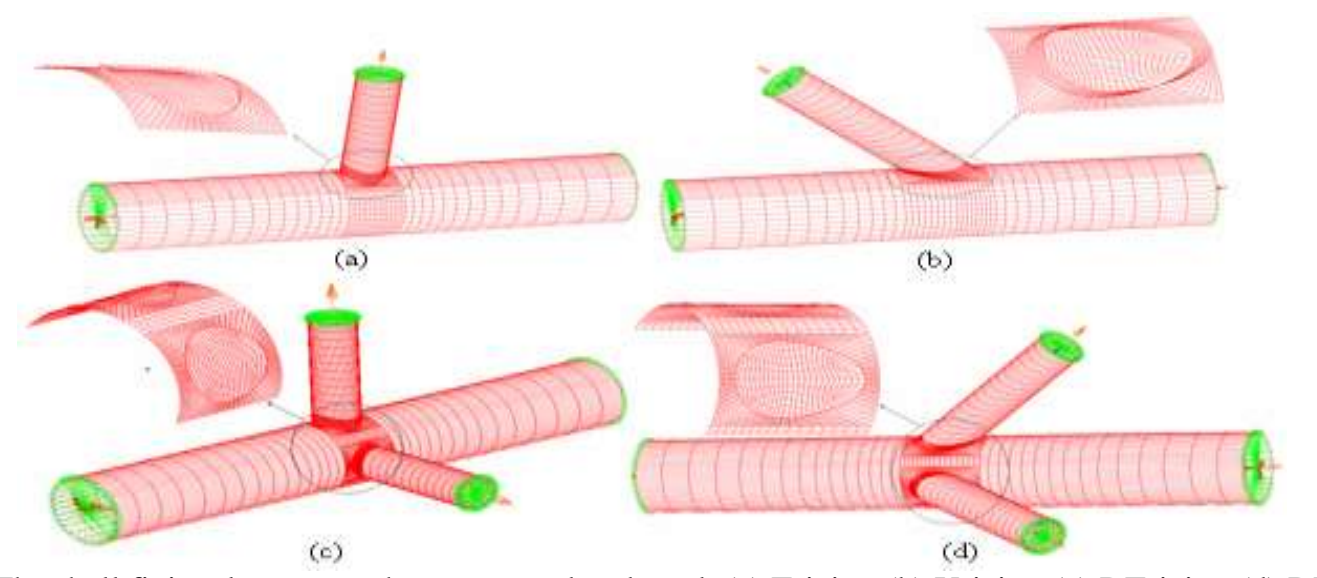

Fig. 1: The shell finite element meshes generated and used, (a) T-joint, (b) Y-joint, (c) DT-joint, (d) DY-joint For all joints: $\mathrm{D}=505.6 \mathrm{~mm}, \alpha=2 \mathrm{~L} / \mathrm{D}=12.66, \beta=\mathrm{d} / \mathrm{D}=0.5, \gamma=\mathrm{D} / 2 \mathrm{~T}=25, \tau=\mathrm{t} / \mathrm{T}=1, \theta=45^{\circ}$

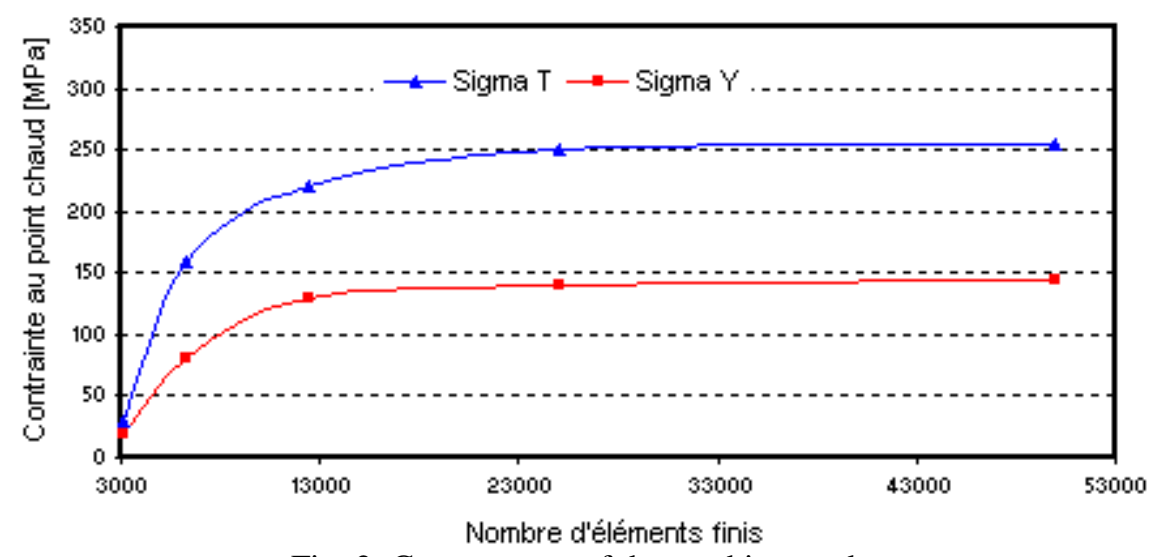

Fig. 2: Convergence of the meshing study

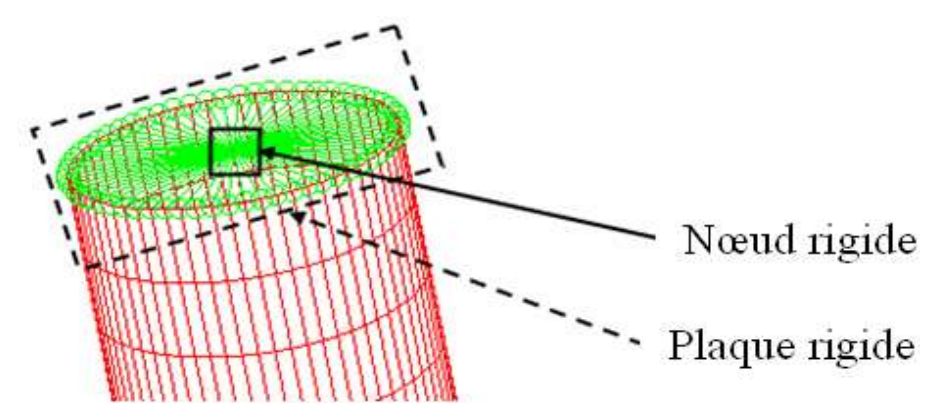

Fig. 3: Rigid node

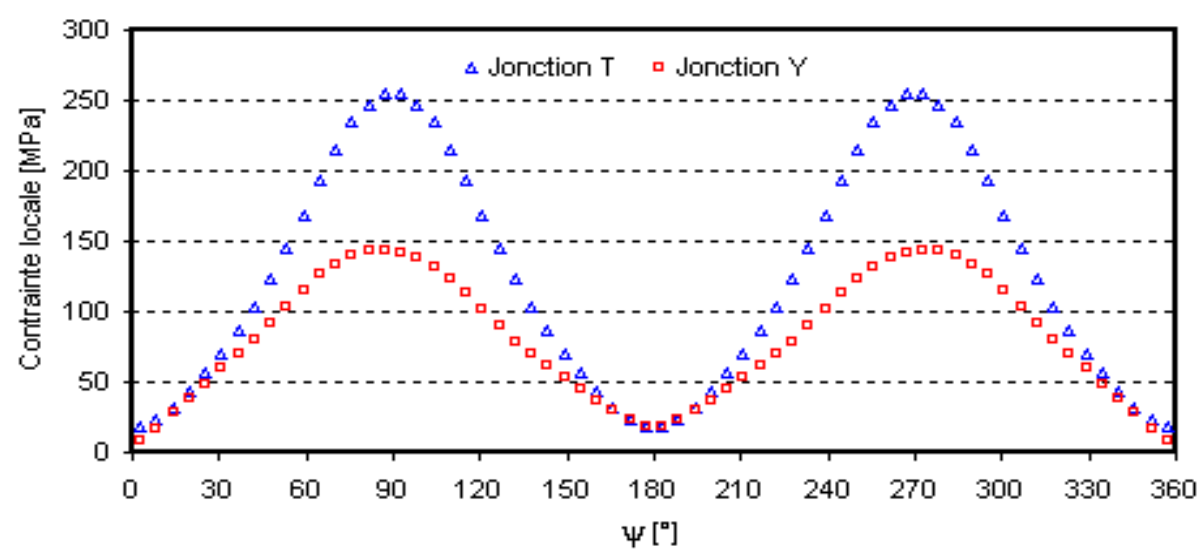

Fig. 4: Geometric stresses around the weld toe in term of $\psi$ counted from crown heel following a tensile force equal to $90 \mathrm{kN}$ 


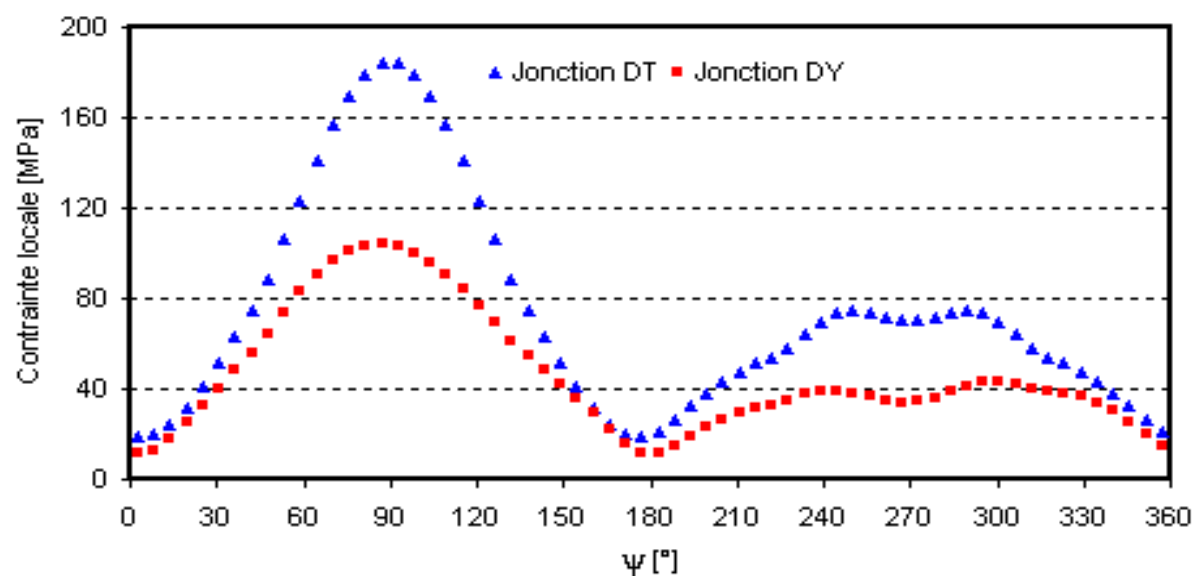

Fig. 5: Geometric stresses around the weld toe in term of $\psi$ counted from crown heel following unbalanced tensile force equal to $90 \mathrm{kN}$

\section{Loading and boundary conditions}

\section{Elastoplastic behaviour}

For comparing the nonlinear responses of planar joints T \& Y and multi-planar joints DT \& DY, the following boundary conditions are imposed:

- Chord's ends are fixed for all joints;

- A proportional and increased tension is applied to the free end of each brace.

In this case, the material is identical to that used in the elastic study, but it's idealized as elastic perfectly plastic.

So, the hardening phenomenon and geometrical instability are neglected.

\section{Limit loads}

Figure 6 shows the variation of tensile force, applied to the brace end, in term of displacement for T and Y-joint. We observe that this force tends to the limit load when the displacement increases. This limit load is equal to $615 \mathrm{kN}$ for T-joint and $910 \mathrm{kN}$ for Y-joint. This proves that the Y-joint is more resistant to the collapse than T-joint. This result confirms the elastic result which says that the SFC for T-joint is more important than Yjoint. This, also, coincides with previous studies that say that the SFC increases in term to angle $\theta$ whose T-joint presents an extremal case for Y-joint with $\theta=90^{\circ}[10,11]$.

The load limit comparison of DT and DY-joint is shown in figure 7. We observe that the limit loads of the DT and DY-joint is in the order of 615MPa and 920MPa respectively. This shows that the DY-joint is more resistant to the collapse that DT-joint.

Until now, we have firstly compared the limit loads between $\mathrm{T}$ and $\mathrm{Y}$-joint, and secondly between DT and DY-joint. In both studies, the joints with inclined braces are more resistant to the collapse than others with perpendicular braces.

Another important observation may be stated, for T and DT-joints, limit loads are respectively $620 \mathrm{kN}$ and $615 \mathrm{kN}$, which are almost the same for Y and DY-joints respectively.

\section{Diffusion of plasticized areas}

T-joint: When the load parameter increase, the plasticized area widens in weld vicinity. The finite elements lose their stiffness progressively, and the load-displacement curve tends towards the limit load. For Tjoint subjected to axial loading, the hot spot is localised in saddle (Fig. 8b). These are the points whose the joint begins to plasticize. To progressively increase the load parameter, the extension of the plasticizing evolves to other areas located midway between crown and saddle (Fig. 8c et d). These figures show, also, that the area whose a big number of finite elements which plasticize the first are not in crown or saddle vicinity. This is the area located midway between these two points (Fig. 8).

Y-joint: As T-joint case, the plasticizing started from saddle. With the increase the external loading, we observe that the red color predominates and tends to fill the crown heel vicinity. We find that even if the hot spot plasticize in the first, the plastic zone is oriented towards the area midway between the saddle and crown heel. We observe, also, an extension of the plastic zone to the central area between saddle and toe crown, but it's not to the same level as the spread recorded between saddle and crown heel (Fig. 9).

DT-joint: The saddles remain elastic under the effect of unbalanced tensile loading. But, the plasticization starts by the outer saddle, followed by the area between the two braces. 
When the external load increases, the plasticization which was initiated at the outer saddle propagates to the area midway between this point and crown, when the area between the two braces continues to plasticize (Fig. 10).

DY-Joint: For this shape, the plasticization starts by the outer saddle before spreading to the area between this point and outer crown heel. The area, between two inclined braces, laminates when the external stress increases, without touching saddle or crown (heel and toe). We observed, also, that the area between crown heel and inter saddle remains elastic all the time with von Mises equivalent stress equal to 58MPa for external loading equal to $560 \mathrm{kN}$.

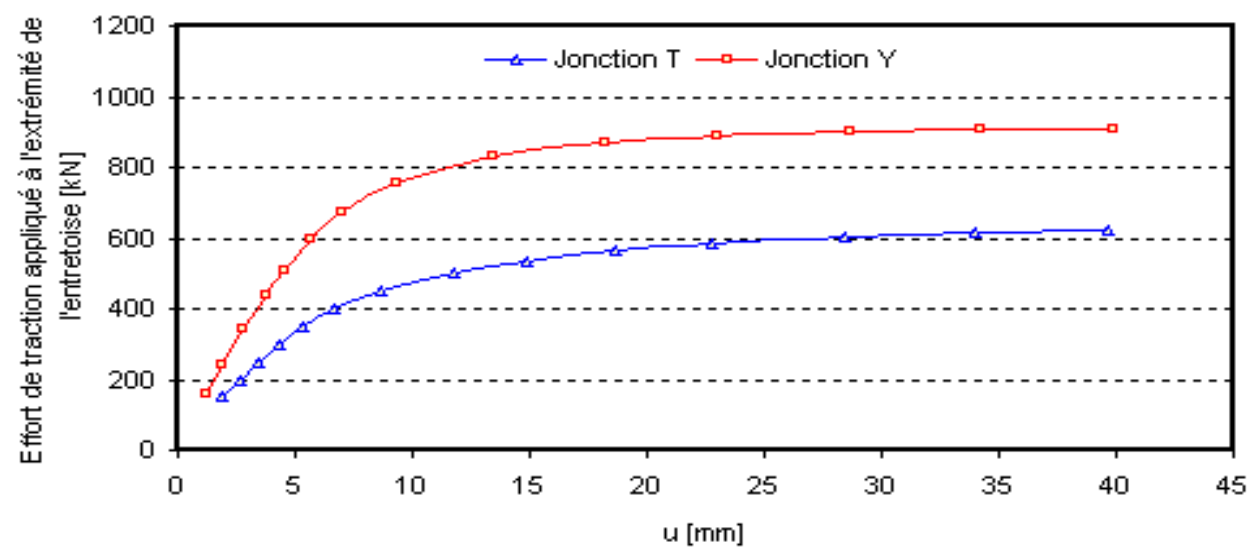

Fig. 6: Limit loads comparison between $\mathrm{T}$ and Y-joint under excessive tensile loads.

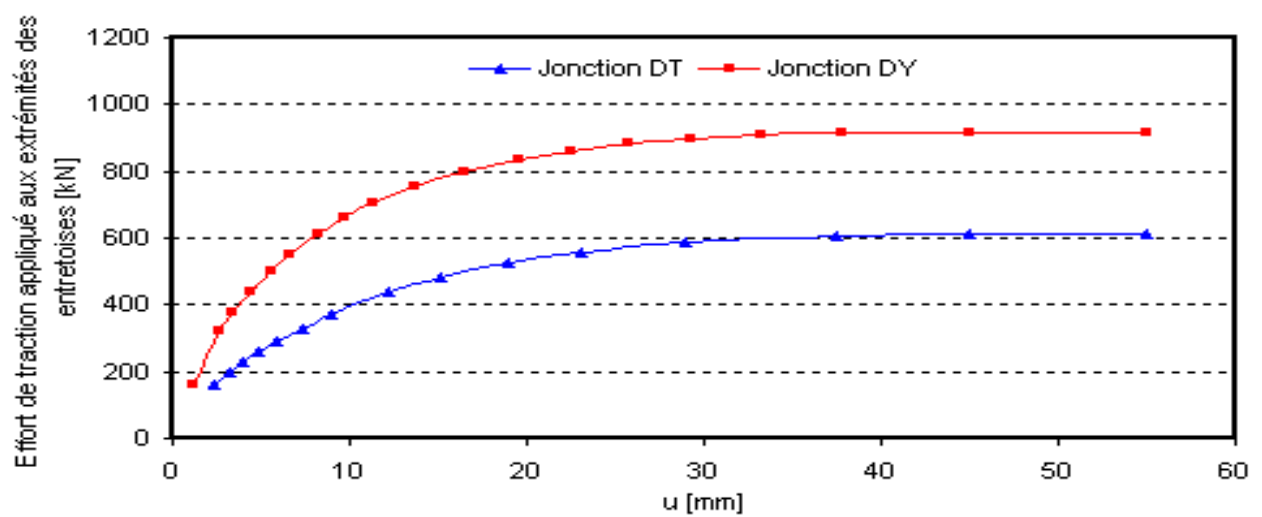

Fig. 7: Limit loads comparison between DT and DY-joint under excessive tensile loads.

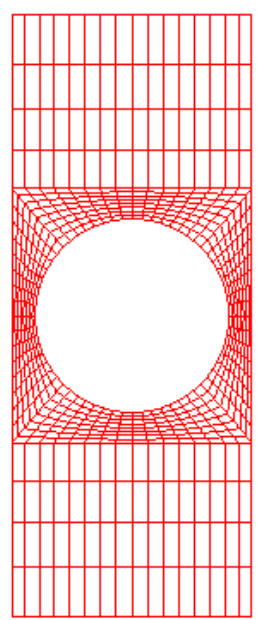

a

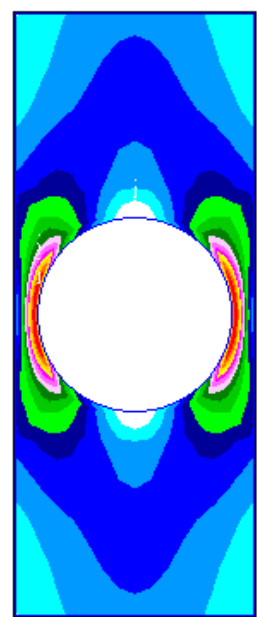

$b$

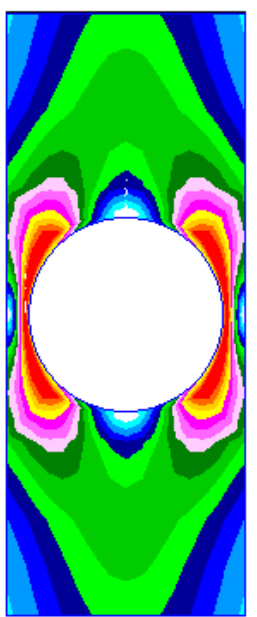

$c$

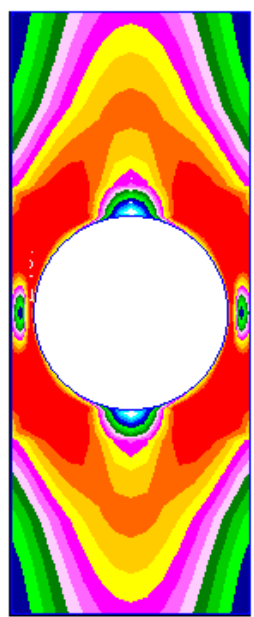

d
Contraintes eq. de Von Mises (MPa)

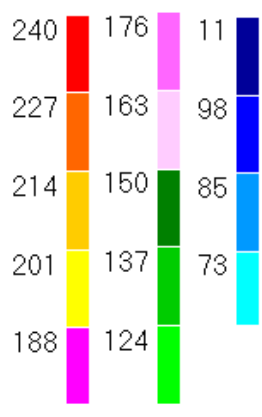

Fig. 8: Critical areas of T-joint following tensile loading:

(a) mesh, (b) iso-stresses at $125 \mathrm{kN}$, (c) iso-stresses at $200 \mathrm{kN}$, (d) iso-stresses at $300 \mathrm{kN}$. 


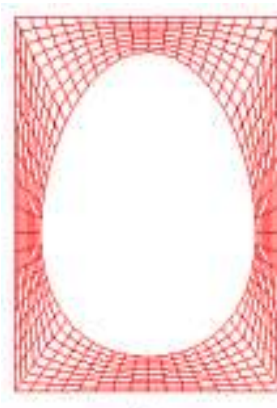

a

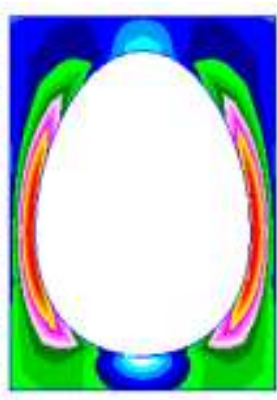

$b$

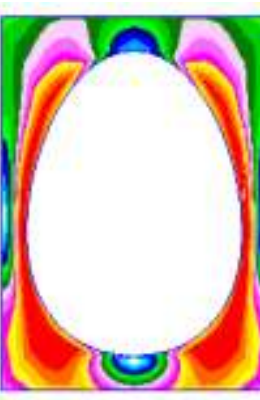

c

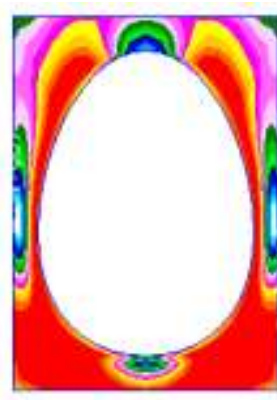

d

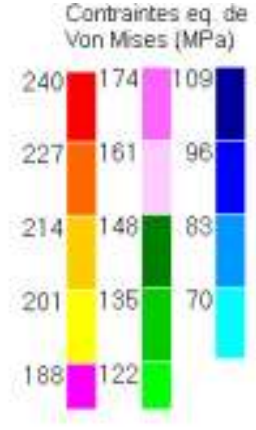

Fig. 9: Critical areas of Y-joint following tensile loading:

(a) mesh, (b) iso-stresses at $240 \mathrm{kN}$, (c) iso-stresses at $400 \mathrm{kN}$, (d) iso-stresses at $480 \mathrm{kN}$.

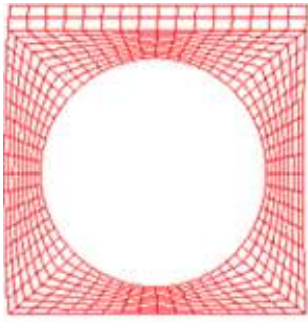

a

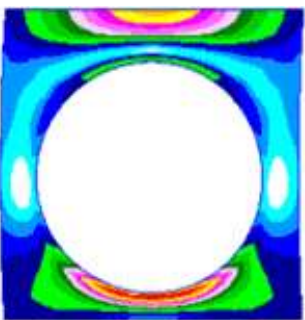

$b$

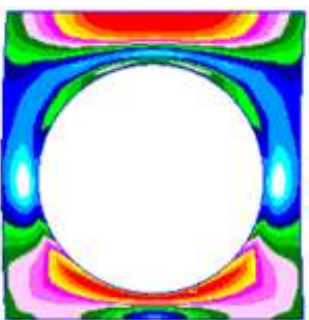

c

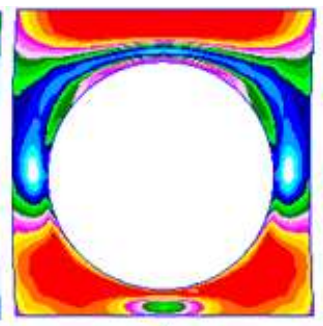

d
Contraintes éq. de

Von Mises (MPa)

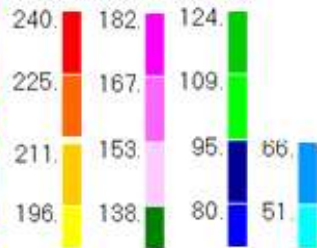

Fig. 10: Critical areas of DT-joint following tensile loading:

(a) mesh, (b) iso-stresses at $160 \mathrm{kN}$, (c) iso-stresses at $240 \mathrm{kN}$, (d) iso-stresses at $320 \mathrm{kN}$.

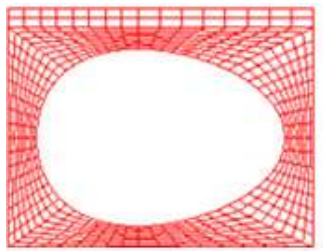

a

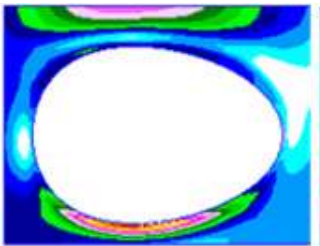

b

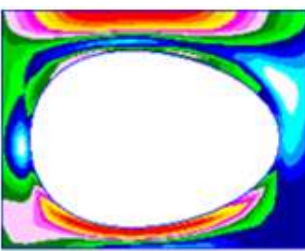

$c$

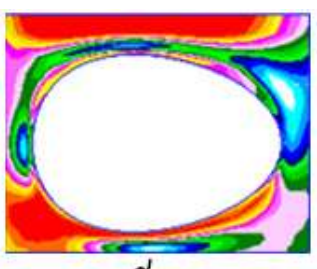

d

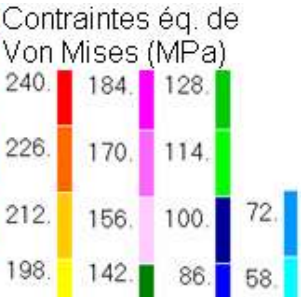

Contraintes eq. de Von Mises (MPa)

240. 184. 128

226. $170 . \quad 114$

198. 142. 86.58

Fig. 11: Critical areas of DT-joint following tensile loading:

(a) mesh, (b) iso-stresses at $160 \mathrm{kN}$, (c) iso-stresses at $400 \mathrm{kN}$, (d) iso-stresses at $560 \mathrm{kN}$.

\section{Conclusions}

The elastic behaviour results of T, Y, DT and DY-joints lead to the following conclusions:

The hot spots are located at the saddles for planar joints ( $\mathrm{T}$ and $\mathrm{Y}$ ) and at external saddle for multi-planar joints (DT and DY).

The SFC for T and DT-joints is greater than SFC for Y and DY-joints respectively. So, joints with inclined braces are stiffer than those with perpendicular braces, whose reinforces the parametric formula results which prove that the SCF increases with the brace inclination angle [10,11].

The proportional and progressive tensile loading, applied to the free ends of braces leads to the following conclusions:

The limit load of Y-joint is greater than these of T-joint. Than, it's concluded that the Y-joint resist better than T-joint to the collapse.

Similarly, the limit load of DY-joint is greater than these of DT-joint. So, DY-joint resist better than DT-joint to the collapse.

Limit loads of T and DT-joints are the same under external tensile loading.

Limit loads of Y and DY are the same under external tensile loading.

Although the initiation of the lamination is located at the saddle (hot spots in the all load cases studied), the plastic zone is diffused to the area midway between saddle and crown heel for planar joints. In multi-planar case, it was found that the plasticization is oriented to the area between the saddle and outer heel crown. 
VII. Notations

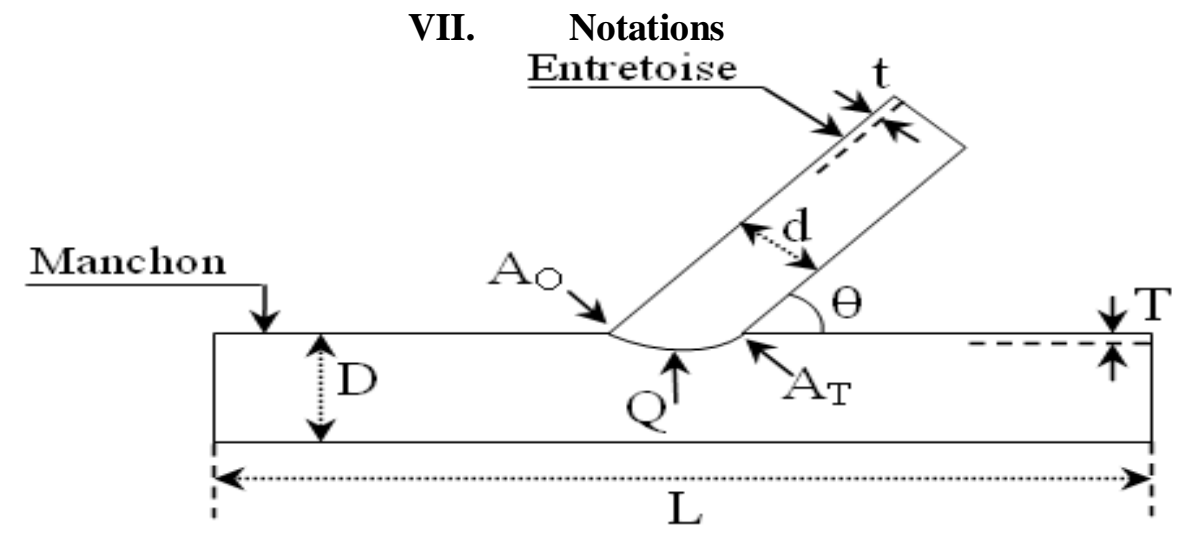

TEN: Tension

OPB: Out of plan bending

IPB: In plan bending

SCF: Stress Concentration Factor

A: Crown

Q: Saddle

$\mathrm{A}_{\mathrm{T}}$ : Crown toe (A with $\psi=0$ )

$\mathrm{A}_{\mathrm{O}}$ : Crown heel (A with $\psi=180^{\circ}$ )

D: Chord diameter

$\mathrm{T}$ : Chord wall thickness

L: Chord length

d: Brace diameter

$\mathrm{t}$ : Brace wall thickness

$\alpha=2 \mathrm{~L} / \mathrm{D}$ : Chord length parameter

$\beta=\mathrm{d} / \mathrm{D}$ : Diameter ratio

$\gamma=\mathrm{D} / 2 \mathrm{~T}$ : Chord thickness ratio

$\tau=\mathrm{d} / \mathrm{D}$ : Wall thickness ratio

$\theta$ : Brace inclination angle

$\psi$ : Angle defining the weld toe orientation counted from crown heel.

\section{References}

[1] H. L. J. Pang, C.W. Lee, Three-dimensional finite element analysis of a tubular T-joint under combined axial and bending loading, International journal of Fatigue, 17(5), 1995, 313-320.

[2] C. Juan, C. Ju, J. Wei-liang, Experiment investigation of stress concentration factor of concrete-filled tubular T joint, Journal of Constructional Steel Research, 66(12), 2010, 1510-1515.

[3] M.F. Ghanameh, D. Thevenet, A. ZEGHLOUL, Evaluation of stress concentration for planar tubular joints, Transactions of Nonferrous Metal Society of China, 16(s1), 2006, s1-s10.

[4] M. M. K. Lee, A. Llewelyn-Parry, Strength prediction for ring-stiffened DT-joints in offshore jacket structures, Engineering Structures, 27(3), 2005, 421-430.

[5] M. M. K. Lee, A. Llewelyn-Parry, Strength of ring-stiffened tubular T-joints in offshore structures: a numerical parametric study, Journal of Constructional Steel Research, 51(3), 1999, 239-264.

[6] C. T. Kang, D. G. Moffat, J. Mistry, Strength of DT Tubular Joints With Brace and Chord Compression, Journal of Structural Engineering, 124(2), 1998, 775-783.

[7] M. M. K. Lee, S. R. Wilmshurst, Numerical modelling of CHS joints with multiplanar double-K configuration, Journal of Constructional Steel Res., 32(3), 1995, 281-301.

[8] A. F. Hamed, Y.A. Khalid, B. B. Sahari, M. M. Hamdan, Finite element and experimental analysis for the effect of elliptical chord shape on tubular T-joint strength, In Journal of Process Mechanical Engineering, 215(part E), 2001, 123-131.

[9] S. Jalal, E. El Maskaoui, A. Mjidila, L. Bousshine, Etude expérimentale et numérique du comportement élasto-plastique d'un joint tubulaire soudé de forme « T », 4th Int. Symposium Aircraft Material, Fès Morocco, 2012.

[10] ARSEM, Guides pratiques sur les ouvrages en mer - Assemblages tubulaires soudés, (TECHNIP: Paris, 1980).

[11] M. F. Ghanameh, Etude numérique et expérimentale des jonctions tubulaires soudées "des plateformes offshore" soumises à des sollicitations complexes, Thèse en Sciences des Matériaux, France, Université Paul Verlaine, Metz, 2007. 